Chang, S. L. (1958). J. gen. Microbiol. 18, 565-578

\title{
Cultural, Cytological and Ecological Observations on the Amoeba Stage of Naegleria gruberi
}

\author{
By S. L. CHANG \\ Robert A. Taft Sanitary Engineering Center, Bureau of State Services, \\ Public Health Service, U.S. Department of Health, Education, \\ and Welfare, Cincinnati, Ohio, U.S.A.
}

SUMMARY: A flagellate amoeba, isolated from Ohio River water and identified as Naegleria gruberi (Schardinger), has been maintained in permanent cultures on a buffered sucrose nitrate agar with its original bacterial associate, identified as Proteus mirabilis. On Czapek agar plates, the growth curve of the amoeba at 25-27 was found to consist of a lag phase of about $4 \mathrm{hr}$., a log growth phase of about $60 \mathrm{hr}$., and a growth-encystment phase of $2-3$ weeks. At $37^{\circ}$ the lag phase was shortened by half and the log growth phase by about a third. The generation time was $4 \frac{1}{2} \mathrm{hr}$. at $25-27^{\circ}$ and $2 \frac{1}{2} \mathrm{hr}$. at $37^{\circ}$. Continuous cultivation at $37^{\circ}$, however, resulted in occurrence of abnormal forms. Very poor growth of amoeba on nutrient and tryptose agars was attributed to their high organic nitrogen content, poor growth in liquid media to the difficulty of amoebae to engulf bacteria. Attempts to grow the amoeba on heat-killed bacteria were failures. Redox potential and $\mathrm{pH}$ determinations revealed that the mixed fluid cultures were aerobic and the amoebae perished at pH values more acid than 5.6. Replacement of Proteus mirabilis by other bacteria by Oehler's technique was unsuccessful because of swarming but was successful with a Flavobacterium sp., which produced a yellow pigment whose antibiotic effect prevented swarming. Permanent cultures of the amoeba with the new bacterial associate were maintained after the amoeba overcame the antibiotic effect of the pigment. Replacement of the Flavobacterium sp. in the mixed culture by new species of bacteria was easily accomplished, and permanent cultures were maintained with Aerobacter aerogenes, Escherichia coli, 8 species of Salmonella and 2 of Shigella. The amoebae encysted earlier on all these species than on Proteus mirabilis.

Cytological observations include: $(a)$ appearance of the chromatin material as short rods; $(b)$ no evidence of thread-like structures radiating from the karyosome or chromatin patches in resting nucleus, nor the centrioles in mitosis; $(c)$ karyosome origin of both the 'interzonal body' and the polar caps.

The cultivation of free-living amoebae has generally been done in broths in the presence of a heterogeneous group of bacteria normally found in water or soil. Growth in such cultures is usually very poor, due to overgrowth of inedible and/or toxic substance-producing bacteria (Singh, 1952). The unsatisfactory results obtained by these workers are reflected by the remark of Dobell (1914) that luck played a great part in determining their success. Credit must be given to Singh $(1941,1945,1946,1948,1950)$ for developing the method of growing amoebae on non-nutrient agar supplemented with edible living bacteria. With this method, however, growth is limited by the supply of bacteria, and two types of cultures are needed for the maintenance of one.

Although the cytology of Naegleria gruberi (Schardinger) has been described in detail and many controversial claims have been clarified (Wilson, 1916; Zulueta, 1917; Kühn, 1920; Ivanić, 1936; Rafalko, 1947; Singh, 1952), gaps 
exist in our knowledge of this subject, especially of the flagellate form. Much remains to be studied of the growth pattern, cultural characteristics and ecological matters relating to both the amoeba and the flagellate form. With a strain of $N$. gruberi isolated from the Ohio River two studies were made to fill these gaps. The present report concerns observations pertaining to the amoeba form of this organism.

\section{METHODS}

Media. Czapek and other standard media were made from Difco Bacto dehydrated products. A buffered sucrose, lactose, maltose, or glucose nitrate agar was compounded with the following ingredients $(\%, w / v): 1$, carbohydrate; $0.2, \mathrm{NaNO}_{3} ; 0.9, \mathrm{NaHPO}_{4} .7 \mathrm{H}_{2} \mathrm{O} ; 0.04, \mathrm{KH}_{2} \mathrm{PO}_{4} ; 0.01, \mathrm{MgSO}_{4} .7 \mathrm{H}_{2} \mathrm{O}$; $0.001, \mathrm{FeSO}_{4} .7 \mathrm{H}_{2} \mathrm{O} ; 1.5$, agar. A buffered sucrose tryptose agar was prepared to contain $(\%, \mathrm{w} / \mathrm{v})$ : 1 , sucrose; 0.2 , tryptose; $0.6, \mathrm{Na}_{2} \mathrm{HPO}_{4} .7 \mathrm{H}_{2} \mathrm{O} ; 0.04$, $\mathrm{KH}_{2} \mathrm{PO}_{4} ; 1 \cdot 5$, agar. The sucrose was omitted in preparing the buffered tryptose agar. For growing mixed cultures of the amoeba and a Salmonella or Shigella sp., the buffered sucrose trypose agar was supplemented with $0 \cdot 1 \%(\mathrm{w} / \mathrm{v})$ glucose. Agar was omitted when these media were prepared in liquid form. The $\mathrm{pH}$ value of the agar medium thus prepared was $7 \cdot 4-7 \cdot 5$ and that of the liquid medium, 7·4-7·6.

All media were autoclaved at $15 \mathrm{lb} . / \mathrm{sq}$.in. for $15 \mathrm{~min}$. Agar plates were poured to a maximum depth that permitted direct microscopic examination through the bottom of the dish. Agar slopes were made in screw-capped $25 \times 150 \mathrm{~mm}$. tubes. Liquid media were dispensed in tubes and in Petri dishes and, for studying $\mathrm{pH}$ value and redox potential changes, in vessels (55 mm. tall and $45 \mathrm{~mm}$. diameter) stoppered with 3-hole rubber stoppers and capped with aluminium foil.

When practical, a potentiometer was used for $\mathrm{pH}$ value and potential measurements (Chang, 1946); otherwise, the $\mathrm{pH}$ changes were roughly indicated by bromothymol blue and methyl red incorporated separately into the media.

Bacteria. Besides the original bacterial associate (Proteus mirabilis), Flavobacterium sp., Aerobacter aerogenes, Escherichia coli, Bacillus subtilis, Pseudomonas pyocyanea, Sarcina lutea, Salmonella typhosa, S. paratyphi, S. schottmuelleri (paratyphi B), S. enteritidis, S. cholerae-suis, S. typhimurium, S. meleagridis, S. pullorum, Shigella dysenteriae II (ambigua), and Sh. sonnei were also studied for their capacity to support amoeba growth. These species of Salmonella and Shigella were obtained from the Communicable Disease Center, Chamblee, Georgia, U.S.A., through Mr B. A. Kenner of the Center. All other species were isolated from Ohio River water.

Flagellate amoeba. The flagellate amoeba was isolated from Ohio River water on Czapek agar containing 100 units penicillin and $200 \mu \mathrm{g}$. streptomycin $/ \mathrm{ml}$. medium. The amoeba was discovered in a mucoid colony of a motile bacillus. After several transfers on the same medium, co-existence of an amoeba and a single species of Gram-negative bacillus became apparent in the mixed culture. When the antibiotics were omitted from the agar, a 
confluent mucoid growth covered almost the entire surface, due to bacterial swarming. Reliance on its bacterial associate for food was evidenced by confinement of the amoeba within the area of bacterial growth and by its feeding freely on the bacteria.

The morphology and cytology of this amoeba are, for the most part, identical with those described by Rafalko (1947) and Singh (1952) for Naegleria gruberi. When its trophozoites were found by accident to undergo flagellate transformation when suspended in water, it was identified as $N$. gruberi. The bacterialassociate was isolated in pure cultures and was identified by biochemical reactions and infrared spectrophotometric characteristics (Riddle et al. 1956) as Proteus mirabilis. Transfers of pure mixed cultures on Czapek agar plates to slopes of the same medium, however, always resulted in rapid death of the amoebae while the $\boldsymbol{P}$. mirabilis maintained rich growth. The death of the amoebae was found to be due to accumulated acids in the mucoid growth at the bottom of the slopes. When buffered sucrose nitrate agar replaced the Czapek agar, rich growth of amoebae was obtained in all slope subcultures.

Replacement of bacterial associate. Because of the relatively poor growth with Singh's method of cultivation, the agar-block technique (cutting out a block of agar plate culture and placing it face-to-face on a new plate to permit migration of the trophozoites away from the area of contact) has generally been used for isolation of amoebae. With the rich growth attained with the present method, the agar-block technique was unnecessary and isolation of the amoeba with or without a new bacterial associate could be done by the 'giant colony' technique (Oehler, 1916). In isolating the amoeba with a new bacterium, a small amount of a mixed culture growth was placed in the centre of an agar plate previously smeared with a suspension of the bacterium. When the new bacterium was edible, trophozoites migrated within a few hours after planting; when not edible, the trophozoites remained in close vicinity of the seeded area. Swarming of the original bacterial associate was prevented by using antibiotics in the inoculum. Penetration of the new bacterium-covered area may be as great as $25 \mathrm{~mm}$. or more within $24 \mathrm{hr}$. Transfer of the growth $1 \mathrm{~cm}$. or farther from the edge of the 'giant colony' usually produced a pure mixed culture of the amoeba and a new edible bacterium.

Cytological examination. The morphology and structure of Naegleria gruberi in the amoeba stage were studied with a phase-contrast microscope supplemented by Feulgen preparations stained by the method described by Singh (1952).

Survival tests of the trophozoites and cysts. The effects of drying on the survival of Naegleria gruberi were determined with growth material containing either trophozoites or cysts dried on slides. Water suspensions of the trophozoites or cysts were placed at $-25^{\circ}$ to $-30^{\circ}$ to test survival under freezing, and in a constant-temperature water bath to test resistance to heat. The effect of $\mathrm{H}^{+}$and $\mathrm{OH}^{-}$ions on cyst survival was determined in $\mathrm{HCl}$ solution, $\mathrm{HCl}+$ $\mathrm{Na}$ acetate and $\mathrm{NaOH}+\mathrm{Na}_{2} \mathrm{HPO}_{4}$ buffers and $\mathrm{NaOH}$ solutions. The test procedure used in studying cysts resistance to $\mathrm{HOCl}$ and $\mathrm{I}_{2}$ was essentially the same as that used in several previous studies made on cysts of Endamoeba histolytica (Chang, 1944; 1955 a). 


\section{RESULTS \\ Growth of Naegleria gruberi on Czapek agar plates in association with Proteus mirabilis}

Growth curve. Repeated examination of large numbers of mixed plate cultures of Naegleria gruberi and Proteus mirabilis incubated at $25-27^{\circ}$ and $37^{\circ}$, showed three distinct phases in the cultural life of the amoeba: lag growth, log growth, and growth encystment.

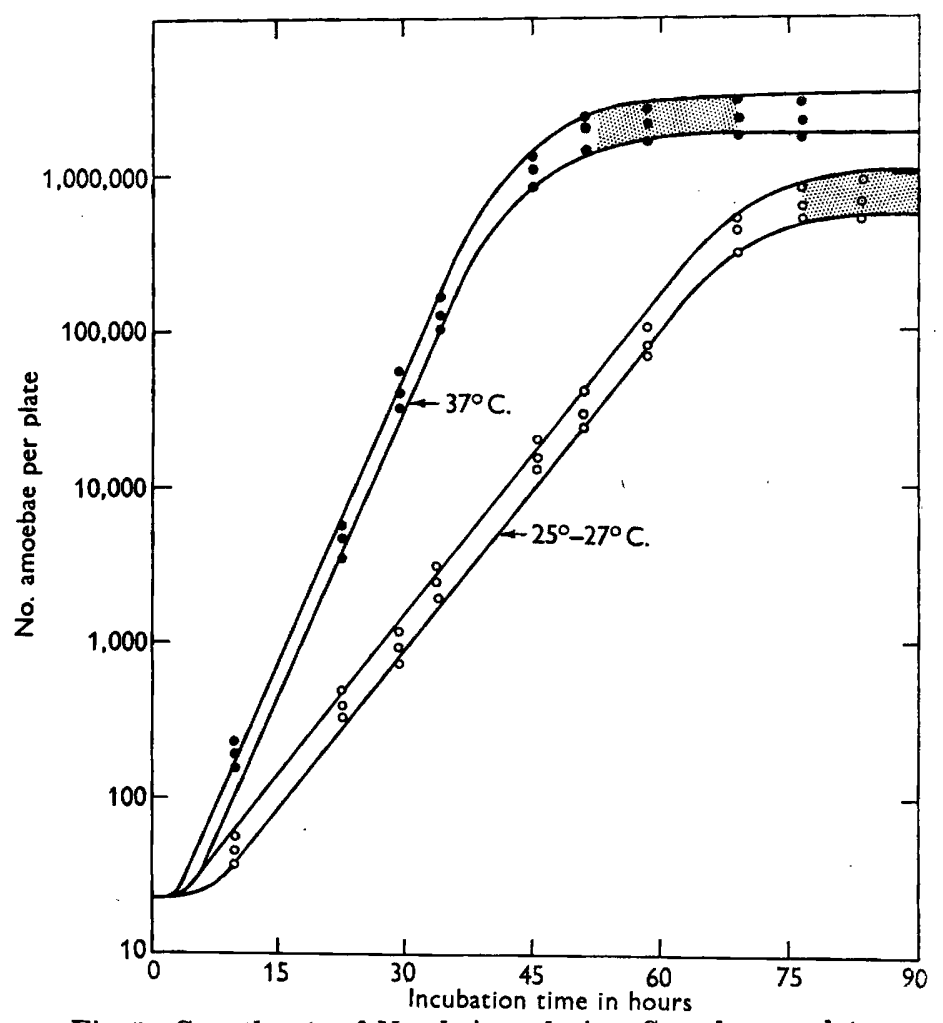

Fig. 1. Growth rate of Naegleria gruberi on Czapek agax plates $\left(25-27^{\circ}\right.$ and $\left.87^{\circ}\right)$. 圈, Mass encystment.

Length of each growth phase and rate of amoeba growth during log growth phase. Each of 6 Czapek agar plates was seeded with a drop of a suspension of young trophozoites and Proteus mirabilis, diluted to contain not more than 50 amoebae/drop. The inoculum was smeared evenly with a sterile L-shaped glass rod over an area about $15 \mathrm{~mm}$. in diameter. The exact number of amoebae on each plate was counted under a low power. Three plates were incubated with the lid uppermost at $37^{\circ}$, and three at $25-27^{\circ}$. Enumeration of amoebae was repeated every $2 \mathrm{hr}$. during the first $8 \mathrm{hr}$; then at suitable intervals during a 3-day period.

Figure 1 indicates that the lag phase lasted about $4 \mathrm{hr}$. at $25-27^{\circ}$ and about $2 \mathrm{hr}$. at $37^{\circ}$, and the $\log$ growth phase about 60 and $40 \mathrm{hr}$., respectively, at 
these temperatures. A short period of slower growth followed the log growth phase and was interrupted by mass encystment, which lasted about $16 \mathrm{hr}$. Multiplication of the few remaining trophozoites contributed little to the total population, which remained more or less stationary during this phase. Later observations on tube cultures maintained on buffered sucrose nitrate agar slopes showed that the log growth and growth-encystment phases were not sharply demarcated and that, after 3-4 days of incubation, encystment and multiplication of trophozoites proceeded side by side in the mucoid deposit for several weeks.

Using conventional equations for computing the growth rate, $k$, and the generation time, $g$, the values of $k(/ \mathrm{hr}$.) and $g(\mathrm{hr}$.) for the growth of Naegleria gruberi under these cultural conditions was found to be 0.68 and 4.5 at $25^{\circ}$ and 1.21 and 2.5 at $37^{\circ}$. These values indicate that a temperature rise of $10^{\circ}$ resulted in almost doubling the growth rate. However, this amoeba is apparently normally adapted to room temperature, and prolonged cultivation at $37^{\circ}$ caused such degenerative changes as the appearance of giant trophozoites, temporary inability to transform into flagellates, etc.

Mass encystment. Initial encystment in a culture of Naegleria gruberi was always a mass phenomenon in which more than $90 \%$ of the trophozoites were involved; it was usually observed in areas where the trophozoites grew into practically a single layer and the surface was relatively dry. Since the supply of bacterial food was still plentiful at this time, it appeared that the process was not stimulated by lack of food but rather by the drying and perhaps by other causes.

Growth of Naegleria gruberi on other agar media in the presence of Proteus mirabilis

Besides the buffered sucrose nitrate agar, other agar media were also used. The results are summarized in Table 1, which also includes the comparative results obtained with Czapek and buffered sucrose nitrate agar. The following results may be noted. First, the good growth of amoebae on Czapek agar plates but not on slopes can be attributed only to changes caused by the way the agar was poured. Since the mucoid growth was spread thin on plates but deposited at the bottom on the slope, and since the $\mathrm{pH}$ value of slope cultures was $\mathbf{0 . 3}$ unit lower than that of plates, it appeared that the short cultural life on slopes was a result of acid accumulation in the growth deposit in which the trophozoites were cut off from contact with air and were more affected by the $\mathrm{pH}$ value than those on plates. Examination of additional slope cultures during the first $24 \mathrm{hr}$. of incubation showed that practically all the trophozoites were washed to the bottom by the increasing amount of mucoid material produced by bacterial growth.

Secondly, the very poor growth of the bacterial associate in buffered lactose (or maltose) nitrate agar, due apparently to its inability to utilize these disaccharides, was accompanied by equally poor growth and early encystment of the amoeba. This observation shows that the amoeba feeds on bacteria and suggests that encystment is stimulated by a lack of food. 
Table 1. Growth of Naegleria gruberi in association with Proteus mirabilis on various agar media incubated at $25-27^{\circ}$

B.S.N.= buffered sucrose nitrate agar; B.L.N.= buffered lactose nitrate agar; B.M.N.= buffered maltose nitrate agar; B.G.N. = buffered glucose nitrate agar; B.S.T. = buffered sucrose tryptose agar; в.т. = buffered tryptose agar.

\begin{tabular}{|c|c|c|c|c|c|c|}
\hline & & & Slope & & Plates & \\
\hline $\begin{array}{l}\text { Agar } \\
\text { medium }\end{array}$ & $\begin{array}{l}\text { Incubation } \\
\text { time (hr.) }\end{array}$ & $\begin{array}{l}\text { Growth of } \\
\text { bacterium }\end{array}$ & $\begin{array}{l}\text { Av. no. amoebae/ } \\
\text { drop deposit }\end{array}$ & $\mathrm{pH}$ & $\begin{array}{l}\text { Av. no. amoebae } \\
\text { micro. field }\end{array}$ & pH \\
\hline Czapek & 24 & Rich & $\begin{array}{l}\text { Less than 100; } \\
\text { motile }\end{array}$ & $5 \cdot 1$ & 100 & $5 \cdot 4$ \\
\hline & 48 & Very rich & All non-motile & $\mathbf{5 \cdot 2}$ & 2500 & $5 \cdot 5$ \\
\hline B.S.N. & $\begin{array}{l}24 \\
48\end{array}$ & $\begin{array}{l}\text { Rich } \\
\text { Very rich }\end{array}$ & $\begin{array}{l}30,000 \\
200,000\end{array}$ & $\begin{array}{l}6 \cdot 4 \\
6 \cdot 6\end{array}$ & $\begin{array}{l}150 \\
3000\end{array}$ & $\begin{array}{l}6 \cdot 6 \\
6 \cdot 7\end{array}$ \\
\hline B.L.N. & $\mathbf{2 4}$ & Very poor & $\begin{array}{l}\text { No deposit, } \\
\text { some growth } \\
\text { on surface }\end{array}$ & $7 \cdot 8$ & 10 & $7 \cdot 4$ \\
\hline & 48 & Very poor & Encystment & $7 \cdot \mathbf{3}$ & Encystment & $7 \cdot 4$ \\
\hline B.M.N. & 24 & Very poor & $\begin{array}{l}\text { Same as on } \\
\text { B.I.N. }\end{array}$ & $7 \cdot 3$ & 10 & $7 \cdot 3$ \\
\hline & 48 & Very poor & Encystment & $7 \cdot 3$ & Encystment & $7 \cdot 3$ \\
\hline B.G.N. & $\begin{array}{l}24 \\
48\end{array}$ & $\begin{array}{l}\text { Rich } \\
\text { Very rich }\end{array}$ & $\begin{array}{l}10,000 \\
50,000\end{array}$ & $\begin{array}{l}5 \cdot 7 \\
5 \cdot 9\end{array}$ & $\begin{array}{l}100 \\
1000\end{array}$ & $\begin{array}{l}6 \cdot 0 \\
6 \cdot 1\end{array}$ \\
\hline B.S.T. & $\begin{array}{l}24 \\
48\end{array}$ & $\begin{array}{l}\text { Rich } \\
\text { Very rich }\end{array}$ & $\begin{array}{l}40,000 \\
300,000\end{array}$ & $\begin{array}{l}6 \cdot 4 \\
6 \cdot 5\end{array}$ & $\begin{array}{l}250 \\
\mathbf{3 5 0 0}\end{array}$ & $\begin{array}{l}6 \cdot 5 \\
6 \cdot 6\end{array}$ \\
\hline B.T. & $\begin{array}{l}24 \\
48\end{array}$ & $\begin{array}{l}\text { Rich } \\
\text { Very rich }\end{array}$ & $\begin{array}{l}\mathbf{4 , 0 0 0} \\
\mathbf{5 0 , 0 0 0}\end{array}$ & $\begin{array}{l}7 \cdot 0 \\
7 \cdot 0\end{array}$ & $\begin{array}{l}50 \\
600\end{array}$ & $\begin{array}{l}7 \cdot 1 \\
7 \cdot 1\end{array}$ \\
\hline Tryptose & $\begin{array}{l}24 \\
48\end{array}$ & $\begin{array}{l}\text { Rich } \\
\text { Very rich }\end{array}$ & $\begin{array}{l}\text { Less than } 100 \\
\text { Few dead ones }\end{array}$ & $\begin{array}{l}6 \cdot 2 \\
6 \cdot 4\end{array}$ & $\begin{array}{l}10 \\
\text { Mostly dead }\end{array}$ & $\begin{array}{l}6 \cdot 3 \\
6 \cdot 4\end{array}$ \\
\hline Nutrient & $\begin{array}{l}24 \\
48\end{array}$ & $\begin{array}{l}\text { Rich } \\
\text { Very rich }\end{array}$ & $\begin{array}{l}\text { Few dead ones } \\
\text { Few dead ones }\end{array}$ & $\begin{array}{l}6 \cdot 6 \\
6 \cdot 5\end{array}$ & $\begin{array}{l}10 \\
\text { Mostly dead }\end{array}$ & $\begin{array}{l}6 \cdot 6 \\
6 \cdot 5\end{array}$ \\
\hline
\end{tabular}

Thirdly, the poorer growth of the amoeba on buffered glucose nitrate agar, on which the bacterial associate flourished, coupled with a more acid $\mathrm{pH}$ value than that given on buffered sucrose nitrate agar, indicates that the more rapid decomposition of glucose than of sucrose resulted in a degree of acid accumulation less favourable for amoeboid growth. The rapid decomposition may also have depleted the carbohydrate supply, thus slowing the rate of multiplication.

Fourthly, the poorer amoeboid growth on buffered tryptose agar than on buffered sucrose tryptose agar, with an equally plentiful bacterial food supply, indicates that the addition of sugar increased the rate of multiplication.

Fifthly, the short cultural life of the amoeba on tryptose and on nutrient agar, on which the bacterial associate grew very well, can be attributed to the high concentration of tryptose, or the peptone and meat extract. This assumption was confirmed when a fairly good amoeboid growth was obtained on tryptose agar in which the tryptose was decreased from 2 to $0.2 \%$, and on nutrient agar in which the peptone and meat extract were both decreased to $0 \cdot 1 \%$. 
Growth of Naegleria gruberi in association with Proteus mirabilis in various media incubated at $\mathbf{2 5 - 2 7 ^ { \circ }}$

Amoeboid growth in liquid media in association with Proteus mirabilis was studied. The results (Table 2) agreed with those in Table 1 in that tubed media tended to accumulate acid at the bottom, thus reducing or even preventing multiplication. They also indicate that the liquid media did not support growth as well as the agars. Other observations, with micro-cultures, showed that the poor growth in liquid media was due to the difficulty of the trophozoites in feeding on freely suspended bacteria, whereas on agars the trophozoites are immediately surrounded by bacteria.

Table 2. Growth of Naegleria gruberi in association with Proteus mirabilis in various fluid media incubated at $\mathbf{2 5 - 2 7 ^ { \circ }}$

B.s.N.=buffered sucrose nitrate solution; B.s.T.=buffered sucrose tryptose broth; B.T. = buffered tryptose broth.

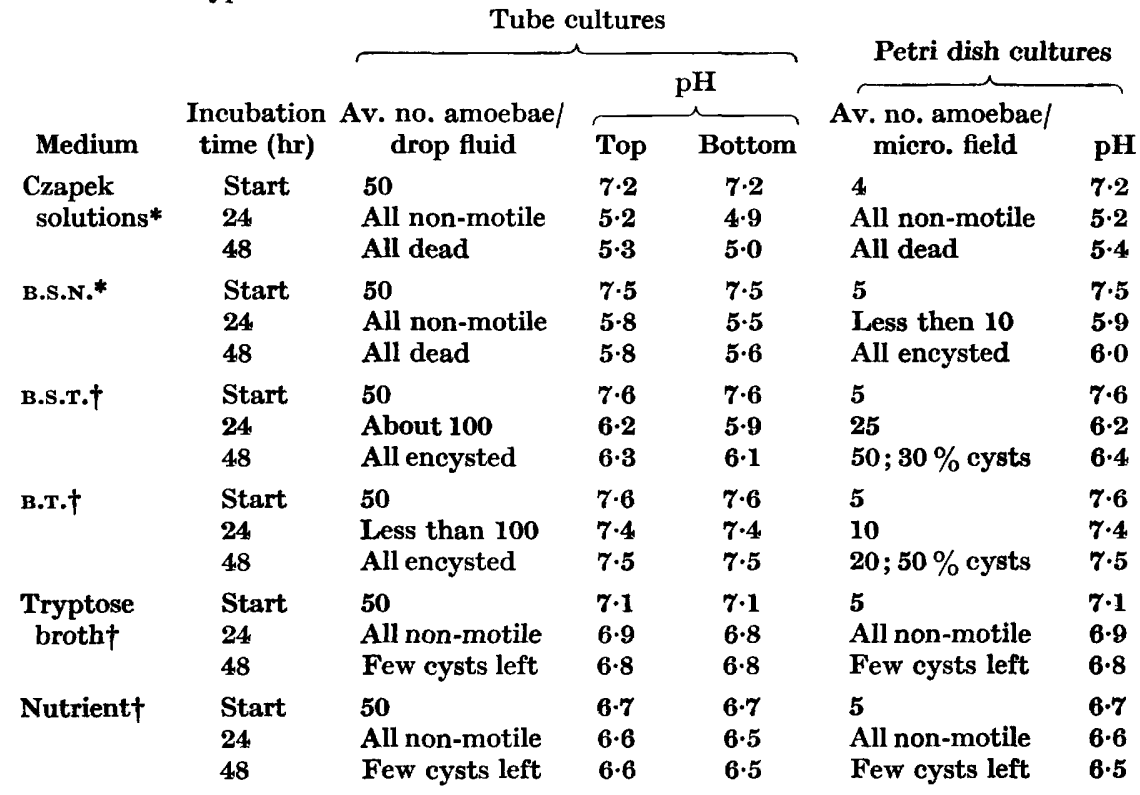

* Good growth of the bacterium-associate judged by the amount of turbidity.

$\uparrow$ Excellent growth of the bacterium-associate.

It appeared that low $\mathrm{pH}$ values were more harmful to amoebae in liquid media than on agar plate cultures. Lowering the $\mathrm{pH}$ value to 5.4 in Czapek solution dispensed in Petri dishes resulted in death, whereas a similar pH lowering exerted no harmful effect on Czapek agar plate cultures. Other observations with trophozoites suspended in water buffered with phosphates at low $\mathrm{pH}$ values $(5 \cdot 2-7 \cdot 0)$ revealed that trophozoites become non-motile and non-feeding, and survived not more than $16 \mathrm{hr}$. at $\mathrm{pH} 5 \cdot 6$ or less. $\mathrm{pH}$ values of 5.6 and less of the liquid media interfered with the physiological 
activities of the trophozoites, such as removal of $\mathrm{CO}_{2}$ from the organism, whereas on agar plates the $\mathrm{pH}$ value seems less likely to interfere with the gas exchange as the trophozoites are in partial contact with the air.

\section{Redox potential and $\mathrm{pH}$ changes in mixed cultures of Naegleria gruberi and Proteus mirabilis}

Since buffered sucrose tryptose broth of the liquid media studied was found to produce the best amoeboid growth this medium was used in studying potential and $\mathrm{pH}$ changes in a mixed culture of these two organisms (Chang, 1946). $\mathrm{E}_{h}$ and $\mathrm{pH}$ values were obtained for each of three replicate cultures, maintained at $25-27^{\circ}$ and $37^{\circ}$. The $E_{h}$ value dropped steadily and sharply during the first $8 \mathrm{hr}$ at $25-27^{\circ}$ and the first $4 \mathrm{hr}$. at $37^{\circ}$ until a value of -110 to $-130 \mathrm{mV}$ was reached. After this decrease, the potential rose steadily to reach +180 to $+200 \mathrm{mV}$ at the end of $24 \mathrm{hr}$. of incubation. Only a $20 \mathrm{mV}$ increase in potential appeared during the remaining 5 days, to give an $E_{h}$ value of +200 to $+220 \mathrm{mV}$ at the end of the 6 th day. The $\mathrm{pH}$ value also dropped steadily to $6.2 \mathrm{in} 12 \mathrm{hr}$. at $25-27^{\circ}$ and in $9 \mathrm{hr}$ at $37^{\circ}$. After the initial decrease there was a slow but steady rise to a value of $7 \cdot 1$ at the end of 6 days. Changes in these cultures would have been considerably greater if the medium had not been so strongly buffered. These results indicate that the mixed culture was, except for the first 8-12 hr. of incubation, an aerobic system, and that decomposition of sucrose with accumulation of acid was most rapid during the first $12 \mathrm{hr}$. at $37^{\circ}$ and the first $24 \mathrm{hr}$. at $25-27^{\circ}$. The redox potential value would still be relatively high even after correction for lowering of the $\mathrm{pH}$ value.

\section{Role of the bacterial associate in the cultivation of Naegleria gruberi}

Attempts were made to replace Proteus mirabilis in the mixed culture by other bacteria. With the richness of amoeboid growth attained in the cultures, the use of the 'agar block' technique was unnecessary and the establishment of a new association could be made by smearing a rich suspension of the new bacterium over the entire surface of a plate of suitable agar medium and placing a small amount of growth material from the old culture at the centre (Oehler, 1916). However, in repeated attempts to replace $\boldsymbol{P}$. mirabilis by Escherichia coli or Aerobacter aerogenes, swarming of the former and the inhibitory effect of antibiotics on the substitute bacterium in the vicinity of the inoculum resulted in failures.

Replacement by a Flavobacterium $s p$. Having found by accident that the Flavobacterium sp. isolated from Ohio River water exhibited some antibiotic effect on Proteus mirabilis and prevented swarming, an effort was made to replace the latter by the former in amoeba cultures. With Oehler's technique, replacement was successful at the first attempt made on buffered sucrose tryptose agar plates. However, during the early subcultures, some difficulty arose from the toxic effect of the yellow pigment, and only those trophozoites in the periphery of the bacterial colonies survived and underwent encystment. A preliminary study with an acetone extract of the flavobacterium showed 
that the pigment inhibited the feeding of the trophozoites on bacteria. This antibiotic effect was temporary, and after four to six subcultures the amoebae apparently developed tolerance to the pigment and grew into cultures as rich as in the presence of Proteus mirabilis. While the general growth pattern was essentially the same, the log-growth phase was shortened by $12-24 \mathrm{hr}$. by early mass encystment. In the new association, the trophozoites were found frequently in areas without bacterial growth, a phenomenon not observed in association with $\boldsymbol{P}$. mirabilis.

Replacement by other bacteria. With mixed cultures of Naegleria gruberi and the Flavobacterium sp., replacement of the bacterial associate was simple provided the replacement bacteria were edible. Up to the present, pure mixed cultures of the amoeba have been maintained with Escherichia coli, Aerobacter aerogenes, on buffered sucrose tryptose agar, and with Salmonella typhosa, S. paratyphi, S. schottmuelleri, S. enteritidis, S. cholerae-suis, S. typhimurium, $S$. meleagridis, $\boldsymbol{S}$. pullorum, Shigella sonnei and $S h$. dysenteriae II on buffered sucrose glucose tryptose agar; but failures were encountered with Bacillus subtilis, Pseudomonas pyocyanea, and Sarcina lutea, attributable, with the last two organisms, to the toxic effect of their pigments.

Growth of Naegleria gruberi in the absence of living bacteria. Numerous plates were prepared on which the trophozoites were free from bacteria. These trophozoites invariably and rapidly underwent encystment, and the cysts failed to excyst unless living edible bacteria were added. Incorporation of vitamins, amino acids and growth factors in the medium failed to alter the fate of these pure cultures, reflecting the complexity of the nutritional requirement. Addition of edible species of bacteria used in the present study but killed by heating at $60^{\circ}$ for 60 min., produced very poor growth. It seems that a thermolabile growth-promoting factor present in the living bacteria is required.

\section{Some cytological observations on Naegleria gruberi}

Size. The size of this amoeba is noticeably influenced by its rate of multiplication, which, in turn, is influenced by food supply. Under cultural conditions in which the trophozoites were supplied with unlimited numbers of bacteria and sufficient carbohydrate, the trophozoites multiplied at maximum rate and the size of the rounded trophozoites at the end of the log growth phase was $18 \mu$. average diameter, whereas under natural conditions in raw river water, the average diameter was $22 \mu$. The size of the cysts depended entirely on the size of the trophozoites undergoing encystment. In general, there is a decrease to three-quarters of the diameter at encystment.

Appearance of cysts. The cysts formed in these cultures were smoother in outline than those illustrated by Singh (1952). Occasionally spindle-shaped cysts were seen in isolated areas of plate cultures. The outer wall of cysts formed on Proteus mirabilis was thicker than those formed with other species of bacteria and had one or two but rarely three pores, filled apparently with a hyaline-like substance ( $\mathrm{Pl}$. 1, fig. 1) which were found to provide exit for the metacystic amoeba. 
Resting nucleus. The trophozoites were usually uninucleate; the frequency of occurrence of binucleate amoebae (Pl. 1, fig. 2) was c. 1 in 300. Uninucleate and binucleate cysts were formed from trophozoites which had the corresponding number of nuclei; amoebae with more than two nuclei were not observed. The newly excysted amoebae had the same number of nuclei as their mother cysts.

Because of its fluidity, the shape of the nucleus changed as the endoplasm flowed from one direction to another during the motion of a trophozoite; it was spherical only when the amoeba was stationary or in the cystic stage. These observations apply also to the karyosome (Pl. 1, figs. 3, 4).

In confirmation of the observations of Singh (1952), the karyosome was Feulgen-negative, sometimes showing one or two areas of lighter intensity which appeared unstained by the light green counter-stain of the Feulgen technique. The nuclear membrane was a delicate structure visible only when the chromatin granules were slightly out of focus (Pl. 1, fig. 4). A single layer of short rod-shaped chromatin granules lay directly beneath and perpendicular to the nuclear membrane. They were more easily seen in cysts than in moving trophozoites (Pl. 1, figs. 1, 2). Thread-like structures radiating from the karyosome as described by Rafalko (1947) and by Singh (1952) were not encountered. Short chromatin rods appeared as chromatin patches (Singh, 1952) when not in sharp focus.

The nucleus in mitosis. The principal nuclear changes observed during mitosis in Naegleria gruberi have been so fully described and illustrated by Rafalko (1947) and Singh (1952) that only the origin and fate of the 'interzonal body' and the polar caps are described here. When the karyosome divides into two polar masses in the prophase, a piece drops out. This piece can be seen through the metaphase and develops into the 'interzonal body' in the anaphase, joining the polar mass in the telophase to form the karyosome of the daughter nucleus. The achromatic polar caps described by Ford (1914) and confirmed by Rafalko (1947) and Singh (1952) derive also from the karyosome. During the early part of the metaphase, a small piece of the polar mass protrudes toward the nuclear membrane and develops into a cap. During the latter part of the anaphase, at about the same time that the 'interzonal body' divides, each polar cap retreats towards the polar mass and fuses with it.

Contrary to Rafalko (1947), and in agreement with Singh (1952), no centrioles were seen at the apex of the polar cap during nuclear division in Naegleria gruberi. In numerous cases of nuclear division no suggestion of centrioles was observed. The observation of Wilson (1916) regarding endogenous budding in $N$. gruberi was not confirmed.

\section{Effect of physical and chemical agents on the survival of trophozoites and/or cysts of Naegleria gruberi}

The results obtained on the effects of drying, freezing and heat on the survival of trophozoites and cysts of the amoeba are summarized in Table 3. Direct microscopic examination of the slides prepared in the drying experiment revealed that the cysts, dehydrated beyond recognition as soon as the water 
Table 3. Effects of drying, freezing and heat on the survival of trophozoites and cysts of Naegleria gruberi

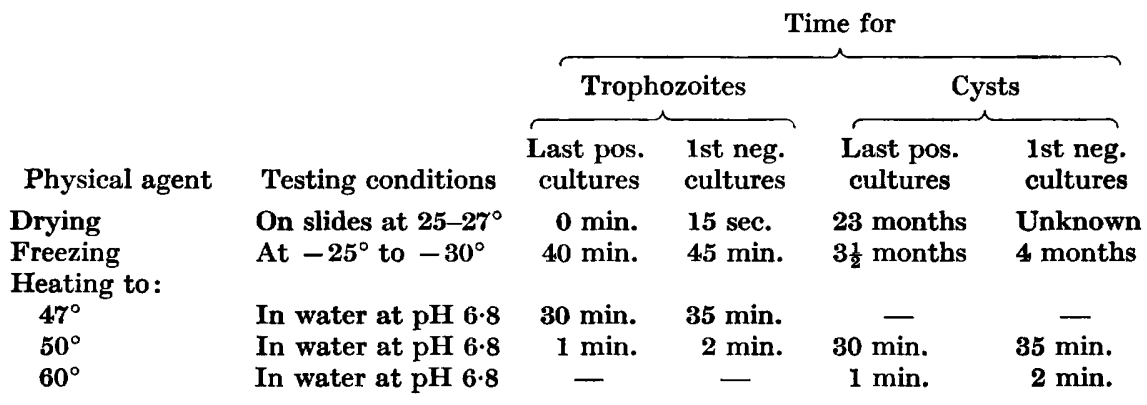

film disappeared, resumed their normal appearance after flooding with water. The trophozoites, on the other hand, appeared dull, granular and shrunk on re-hydration, even when water was added within a few seconds after drying.

The results obtained in experiments on destruction of cysts by $\mathrm{H}^{+}$and $\mathrm{OH}^{-}$ion, $\mathrm{HOCl}$ and $\mathrm{I}_{2}$ are shown in Table 4 .

Table 4. Resistance of cysts of Naegleria gruberi to $\mathrm{H}^{+}$and $\mathrm{OH}^{-}$ion, $\mathrm{HOCl}$ and $\mathrm{I}_{2}$ at $25-27^{\circ}$

\begin{tabular}{|c|c|c|c|c|}
\hline \multirow[b]{3}{*}{ Chemical agent } & \multirow{2}{*}{\multicolumn{2}{|c|}{ Concentration }} & \multirow{2}{*}{\multicolumn{2}{|c|}{ Time for }} \\
\hline & & & & \\
\hline & Initial & Residual & cultures & cultures \\
\hline $\mathbf{H}^{+}$ & 一 & $\equiv \mathrm{pH} 0.5$ & $2 \frac{1}{4} \mathrm{hr}$. & Undetermined \\
\hline $\mathbf{O H}^{-}$ & 一 & $\equiv \mathrm{pH} \mathrm{14.0}$ & $5 \mathrm{~min}$. & $10 \mathrm{~min}$. \\
\hline $\mathrm{HOCl} *$ & 1.8 p.p.m. & 1.5 p.p.m. & $30 \mathrm{~min}$. & 35 min. \\
\hline & 4.0 p.p.m. & 3.5 p.p.m. & $10 \mathrm{~min}$. & 15 min. \\
\hline $\mathbf{I}_{2}$ & $\begin{array}{l}2.5 \text { p.p.m. } \\
4.5 \text { p.p.m. }\end{array}$ & $\begin{array}{l}2.0 \text { p.p.m. } \\
4.0 \text { p.p.m. }\end{array}$ & $\begin{array}{l}30 \text { min. } \\
10 \text { min. }\end{array}$ & $\begin{array}{l}35 \text { min. } \\
15 \text { min. }\end{array}$ \\
\hline
\end{tabular}

* Expressed as titratable chlorine.

\section{DISCUSSION}

The study of the nutritional requirements of Naegleria gruberi was handicapped by the need for edible living bacteria, but this need reflects the nutritional complexity of the amoeba. In practice, this method of cultivation offers a reproducible procedure by which the cultural characteristics of the amoeba can be studied. The growth rate of $N$.gruberi at room temperature determined in the present work is not significantly different from that of Endamoeba histolytica at $37^{\circ}$ as computed from data of Balamuth \& Howard (1946) and of Phillips \& Rees (1950). On the other hand, it is considerably higher than that of Tetrahymena geleii at $25^{\circ}$ (Kidder \& Dewey, 1949) and of haemoflagellates at $22 \cdot 5-32^{\circ}$ (Chang \& Negherbon, 1947).

The selectivity of Naegleria gruberi for species of bacteria as food is a subject of considerable interest. Singh $(1941,1942 a, b, 1945)$ showed that freeliving amoebae fed selectively on various bacteria species, generally excepting 
those which produce red, violet, blue, green or fluorescent pigments. In the present work, it was found that all species of Salmonella and Shigella tested, Escherichia coli, Aerobacter aerogenes, Proteus mirabilis, and a Flavobacterium sp. were edible but that the last one exhibited a temporary antibiotic effect. Bacillus subtilis, Sarcina lutea, and Pseudomonas pyocyanea were inedible, the last two because of the toxic effect of their pigments toward which the amoeba did not acquire tolerance as it had towards the yellow pigment of the flavobacterium. The edibility of Salmonella and Shigella organisms by amoebae has some sanitary significance. It indicates that in sewage treatment, as well as in natural purification of polluted water, this method of feeding may be responsible, at least in part, for the diminution in numbers of pathogenic bacteria. In this connexion Staal (1954) reported the feeding of Paramecium on E. coli, Micrococcus pyogenes var. aureus, S. typhimurium, S. enteritidis, and $B$. subtilis, the harmful effect of $\boldsymbol{E}$. coli and $S$. typhimurium on the predator, and that as many as 10,000 bacteria may be consumed/Paramecium/hr. Since Staal used killed organisms stained with a dye to facilitate observation, his results may not be applicable to protozoa feeding on living bacteria. In practice, both observations indicate the presence in sewage and natural waters of predators which would substantially decrease the numbers of enteric pathogens. Results obtained on amoeboid growth with $\boldsymbol{P}$. mirabilis on various agar media strongly indicate that while the amoeba relies on the bacteria for food, utilization of this food is improved by the presence of a carbohydrate.

While observations on redox potential changes in mixed cultures of Naegleria gruberi and Proteus mirabilis indicate a relatively aerobic system, they do not rule out amoeboid growth under an anaerobic system. Rafalko (1947) claimed that $N$. gruberi grew in faecal suspension but made no mention of degree of growth nor of the period for which his cultures were maintained.

The practically instant death of trophozoites and the extremely long survival of cysts of Naegleria gruberi under drying conditions indicate some fundamental difference in the organization of the protoplasm as between the vegetative and resting forms. Since the cysts rapidly restored their normal appearance upon re-hydration while the trophozoites showed signs of permanent changes, it appears that the amoeba undergoes a reorganization of the protoplasm in encystment which enables the cysts to survive dehydration. This ability shows a difference between cysts of $N$. gruberi and those of $E$ ndamoeba histolytica, since the latter die almost instantaneously upon drying (Chang, 1943).

Results on the survival of trophozoites and cysts of Naegleria gruberi under freezing conditions compare with those under drying. It was stated (Chang, $1955 \mathrm{~b}$ ) that freezing kills cysts of Endamoeba histolytica by denaturation of protoplasmic proteins through crystallization of their water content. If this hypothesis is applicable to $N$. gruberi, one would expect rather rapid death of trophozoites and long survival of cysts on freezing. As expected, the survival time of trophozoites of $N$. gruberi at $-25^{\circ}$ to $-30^{\circ}$ was about $40 \mathrm{~min}$., the time required for freezing the suspension. However, the 3- to 4-month survival of the cysts when frozen as against the 23-month or longer survival when dried 
remains unexplained. The data on the destruction of cysts by $\mathrm{H}^{+}$and $\mathrm{OH}^{-}$ ion, $\mathrm{HOCl}$ and $\mathrm{I}_{2}$ obtained here strongly indicate that while these cysts survive much longer periods in a dehydrated state than those of Endamoeba histolytica, they are only slightly more resistant to these chemical agents than are the latter (Fair, Chang \& Morris, 1945; Fair, Morris \& Chang, 1947; Chang $\&$ Morris, 1953). Hence, it seems that cysts of $N$ gruberi might be used advantageously as a substitute for those of $\boldsymbol{E}$. histolytica in cyst-destruction studies.

\section{REFERENCES}

Batamuth, W. \& Howard, B. (1946). Biological studies on Endamoeba histolytica. I. The growth cycle of populations in a mixed bacterial flora. Amer. J. trop. Med. 26, 771.

Chang, S. L. (1943). Studies on Endamoeba histolytica. II. Observations concerning encystation, maturation, and excystation of $E$. histolytica, and on the longevity of culture-induced cysts in various fluids and at different temperatures. J. infect. Dis. 72, 232.

Chang, S. L. (1944). Studies on Endamoeba histolytica. III. Destruction of cysts of $E$. histolytica by a hypochlorite solution, chloramines in tap water and gaseous chlorine in tap water of varying degree of pollution. War Med., Chicago, 5, 46.

Crang, S. L. (1946). Studies on Endamoeba histolytica. IV. The relation of oxidationreduction potential to the growth, encystation, and excystation of $E$. histolytica in culture. Parasitology, 37, 101.

Chang, S. L. $(1955 a)$. Studies on destruction of eysts of Endamoeba histolytica. I. Establishment of the order of reaction in destruction of cysts of $\boldsymbol{E}$. histolytica by elemental iodine and silver nitrate. Amer. J. Hyg. 61, 121.

Chang, S. L. $(1955 b)$. Survival of cysts of Endamoeba histolytica in human faeces under low-temperature conditions. Amer. J. Hyg. 61, 103.

Chang, S. L. \& Morris, J. C. (1953). Elemental iodine as a disinfectant for drinking water. Industr. Engng Chem. 45, 1009.

Chang, S. L. \& Negherbon, W. C. (1947). Studies on haemoflagellates. II. A study of the growth rates of Leishmania donovani, L. brasiliesis, L. tropica, and Trypanosoma cruzi in culture. $J$. infect. Dis. $80,172$.

Dobell, C. (1914). Cytological studies on three species of Amoeba-A. lacertae Hartmann, A. glebae n.sp., A. fluvialis n.sp. Arch. Protistenk. 34, 139.

Fair, G. M., Chang, S. L. \& Morris, J. C. (1945). Final Report to the Committee on Medical Research on Disinfection of Water and Related Substances, p. 177.

FAIr, G. M., Morris, J. C. \& Chang, S. L. (1947). Dynamics of water chlorination. J. New Engl. Wat. Whs Ass. 61, 285.

Ford, E. (1914). On the nuclear division of a free-living limax amoeba (Amoeba tachypodia Glaser?). Arch. Protistenk. 34, 190.

IvanIĆ, M. (1936). Über die mit den Regulationsvorgängen des Kernapparatus verbundene Ruhestadien bildung bei Vahlkampfia danubiensis s.nov. Arch. Protistenk. 88, 421.

KIDDER, G. W. \& DeWEy, V. C. (1949). Studies on the biochemistry of Tetrahymena. XI. Components of Factor II of known chemical nature. Arch. Biochem. 20, 433.

KüHN, A. (1920). Untersuchungen zur kausalen Analyse der Zellteilung. I. Zur Morphologie und Physiologie der Kernteilung von Vahlkampfia bistadialis. Arch. EntreMech. Org. 46, 259.

Oferler, R. (1916). Amöbenzucht auf reinem Boden. Arch. Protistenk. 37, 175.

Phillips, B. P. \& Rees, C. W. (1950). The growth of Endamoeba histolytica with live and heat-treated Trypanosoma cruzi. Amer. J. trop. Med. 30, 185.

Rafalko, J. S. (1947). Cytological observations on the amoeba-flagellate, Naegleria gruberi (Protozoa). J. Morph. 81, 1. 
Riddle, J. W., Kabler, P. W., Kenner, B. A., Bordner, R. H., Rockwood, S. W. \& Stevenson, H. J. R. (1956). Bacterial identification by infrared spectrophotometry. J. Bact. 72, 593.

SiNGH, B. N. (1941). Selectivity in bacterial food by soil amoebae in pure mixed cultures and in sterilized soil. Ann. appl. Biol. $28,52$.

Singh, B. N. (1942a). Selection of bacterial food by soil flagellates and amoebae. Ann. appl. Biol. 29, 18.

Singh, B. N. (1942b). Toxic effects of certain bacterial metabolic products on soil protozoa. Nature, Lond. 149, 168.

Singr, B. N. (1945). The selectivity of bacterial food by soil amoeba, and the toxic effects of bacterial pigments and other products on soil protozoa Brit. J. exp. Path. 26, 316.

SiNGH, B. N. (1946). A method of estimating the number of soil protozoa, especially amoeba, based on their differential feeding on bacteria. Ann. appl. Biol. 33, 112.

Singh, B. N. (1948). Studies on giant amoeboid organisms. 1. The distribution of Leptomyxa reticula Goodey in soils of Great Britain and the effect of bacterial food on growth and eyst formation. J. gen. Microbiol. 2, 8.

Singh, B. N. (1950). A culture method for growing small free-living amoebae for the study of their nuclear division. Nature, Lond. 165, 65.

SiNGH, B. N. (1952). Nuclear division in nine species of small free-living amoebae and its bearing on the classification of the order Ameobida. Phil. Trans. B, 236, 405.

StaAl, B. H. (1954). Untersuchungen über die Rolle der Ciliaten als Bakterienvernichter in Rahmen der biologischen Reinigung des Abwassers. Z. Hyg. InfektKr. 139, 160.

Wirson, C. W. (1916). On the life history of a soil amoeba. Univ. Calif. Publ. Zool. $16,241$.

Zulueta, A. (1917). Promitosis y sindiéresis, dos modos de división nuclear coexistentes en Amoebas del grupo Limax. Trab. Mus. Cienc. nat., Madr., ser. Zool. no. 33.

\section{EXPLANATION OF PLATE}

Phase-contrast micrographs of trophozoites and cysts of Naegleria gruberi.

Fig. 1. A cyst showing the outer wall and its pore, and chromatin rods arranged perpendicular to nuclear membrane.

Fig. 2. A binucleate cyst.

Fig. 3. A trophozoite showing the nucleus.

Fig. 4. A dividing trophozoite showing the nuclear membrane or chromatin and the karyosome of each nucleus. 
Journal of General Microbiology, Vol. 18, No. 3
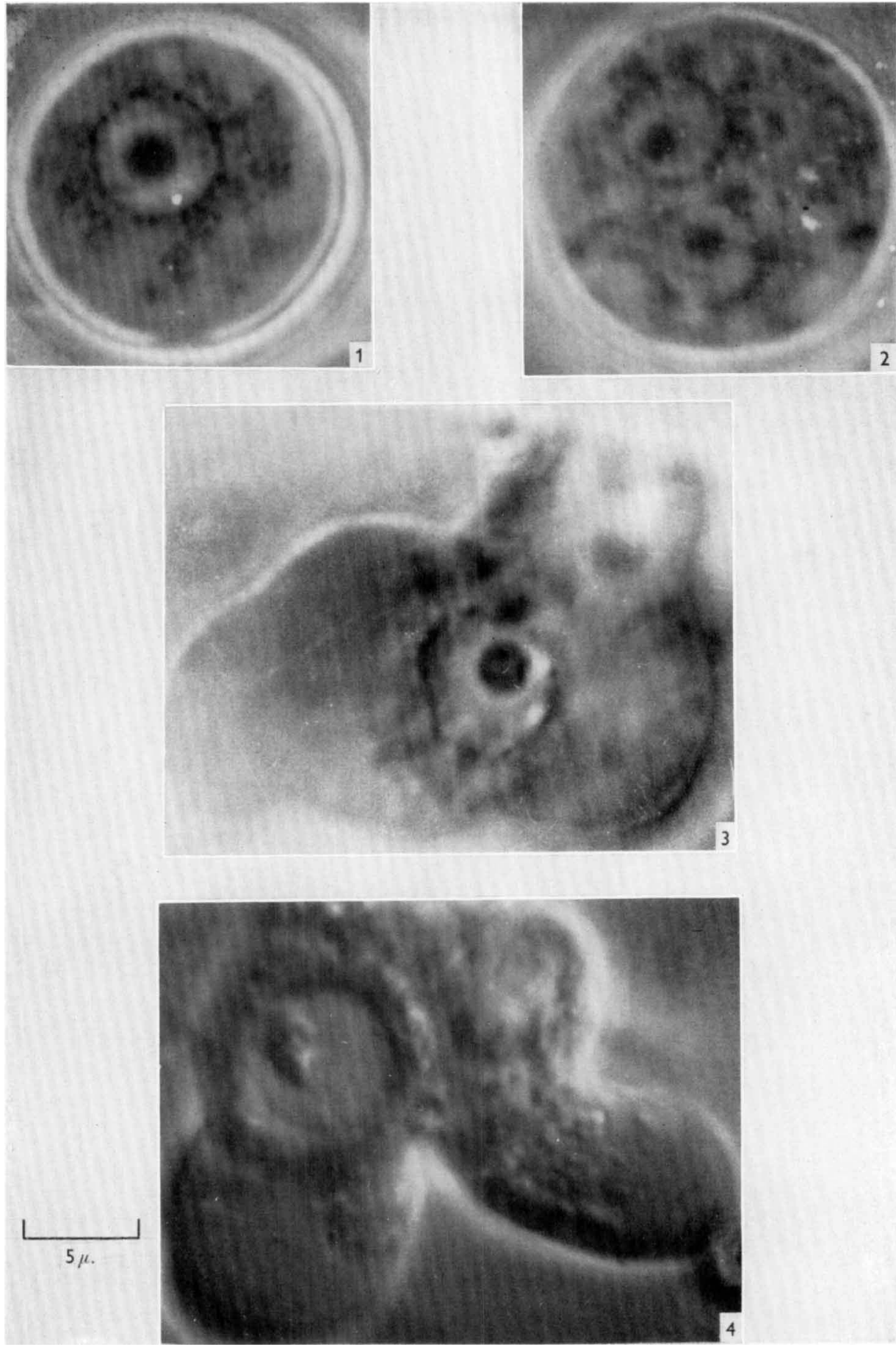

S. I. Chang--Amoeba stage of Nabglerta greberi. Plate 1 